\title{
Article \\ Food Waste Drivers in Corporate Luxury Hotels: Competing Perceptions and Priorities across the Service Cycle
}

\author{
Gaurav Chawla ${ }^{1}$, Peter Lugosi ${ }^{2, *(\mathbb{D})}$ and Rebecca Hawkins ${ }^{2}$ \\ 1 South Wales Business School, University of South Wales, Newport NP20 2BP, UK; \\ gaurav.chawla@southwales.ac.uk \\ 2 Oxford Brookes Business School, Oxford Brookes University, Oxford OX3 0BP, UK; rjhawkins@brookes.ac.uk \\ * Correspondence: plugosi@brookes.ac.uk
}

check for updates

Citation: Chawla, G.; Lugosi, P.; Hawkins, R. Food Waste Drivers in Corporate Luxury Hotels: Competing Perceptions and Priorities across the Service Cycle. Tour. Hosp. 2021, 2 , 302-318. https://doi.org/10.3390/ tourhosp2030019

Academic Editor: Brian Garrod

Received: 21 May 2021

Accepted: 6 July 2021

Published: 9 July 2021

Publisher's Note: MDPI stays neutral with regard to jurisdictional claims in published maps and institutional affiliations.

Copyright: (c) 2021 by the authors. Licensee MDPI, Basel, Switzerland. This article is an open access article distributed under the terms and conditions of the Creative Commons Attribution (CC BY) license (https:/ / creativecommons.org/licenses/by/ $4.0 /)$.

\begin{abstract}
Drawing on data gathered through semi-structured interviews, participant observation and document analysis at five-star hotels in UK and Germany, this paper examines the competing pressures driving waste generation and prevention at different stages in the food production and service cycle. Primary data indicated that senior managers recognised the potential savings that could be achieved by preventing food waste. Despite this, many wasteful practices were normalised within routine operations. This was partly attributed to the corporatised business model and brand strategy in which premium pricing and luxury experiential propositions potentially transformed food waste reduction strategies into sources of risk. Past research generally categorised food as being edible or inedible. In contrast, the terms usable/unusable are proposed and this paper discusses how corporatised practices and value propositions rendered usable foods unusable. It considers how this type of corporate system frames waste problems and thus solutions, leading to various consequences. The discussion also explores how those systems shaped the organisational culture and the agency of staff who engaged with the service cycle at and across multiple points. The findings of this paper are based on primary data collected from a small number of corporately governed luxury hotels. Consequently, the closing parts of this paper outline how the insights generated here could be applied to the study of alternative organisational arrangements and operational types.
\end{abstract}

Keywords: food waste; food production; food service cycle; luxury hotels; breakfast service

\section{Introduction}

Waste in general and food waste in particular is a major sustainability challenge [1]. The topic has become a significant policy issue globally due to negative social, economic and ecological costs associated with food production, waste generation and disposal [2]. Hotels have often attracted criticism for being wasteful, and research has highlighted the severe environmental impacts of the waste they produce [3]. Consequently, waste prevention is of critical importance for the sector for financial, marketing, legal and ethical reasons. Hotels produce various types of packaging, glass, paper and water waste, but food waste in particular has become a focus of interest among academics, business managers and policy makers [4]. Increased attention toward this issue is warranted as food is the second largest contributor to overall waste generated by the hospitality and foodservice sector [5]. For example, in the UK alone, a recent study suggested that the sector produced $7.5 \%$ more waste compared to the baseline, while waste produced by all other sectors declined [6]. This suggests that current measures to reduce food waste have proven to be ineffective.

Food waste is a global problem. It is estimated that 1.3 billion tonnes of food are wasted per annum globally [7]. This, in absolute terms, represents between one-third and a half of all food produced $[8,9]$. Hence, food waste is a major contributor to greenhouse gas emissions [10]. Wastage of food also implies that water, energy and nutrients used to produce the food are also lost. The economic value of food wasted globally is estimated to 
be approximately 1000 billion dollars per annum [11]. At the same time, it is difficult to reconcile wastage with rising food poverty [12]. Given the negative socio-economic and environmental consequences of food waste, the topic has been included in the United Nations' Sustainable Development Goals [13]. Nevertheless, wastage of edible food continues to be a reality in both domestic and commercial spaces [14].

The hospitality sector is the third largest contributor to food waste in Europe [15]. A study from the USA presented similar results, as $17 \%$ of total food waste generated in the country was attributed to the hospitality and food service industry [16]. In the UK, the sector is responsible for $10 \%$ of food waste nationally [17]. This, in absolute terms, is estimated to be 1.1 million tonnes of food [18]. It has been argued that wasted food costs the UK hospitality and food service sector $£ 2.5$ billion per annum [5]. This is equivalent to one meal for every six served. Interestingly, three-quarters of food waste produced by the sector was seen as avoidable [5]. This implies that there are significant opportunities for waste prevention. It has been estimated that hotels in the UK produced 79,000 tonnes of food waste in 2012 [5]. In financial terms, this represents a cost of $£ 318$ million to the industry. Similar findings were reported from Malaysia too, as a recent study found that five-star hotels wasted as much as $173.2 \mathrm{~kg}$ of food per day [19]. This suggests that the issue of wastage is pervasive in the hotel industry.

Despite this, much research on food waste has primarily focused on domestic consumption and scholarly work located in the hotel sector remains limited [4,19-21]. Researchers continue to stress that there is inadequate knowledge of management practices and underpinning attitudes in the production realm, calling for further studies to understand the causes and drivers of food waste in diverse foodservice settings [22-24]. Studies conducted in hotels often focus on consumer behaviours and plate waste [25], and exploratory studies of staff attitudes and behaviours and waste arising elsewhere in the food system are only gradually emerging [26-28]. Waste mapping and material flow analysis [20] are increasingly finding favour with hoteliers. However, the usefulness of these techniques is limited to simply quantifying waste arising in various operational areas. The exact causes and drivers for waste remain poorly understood. This paper responds to these gaps in knowledge regarding food waste production, prevention and the tensions between these forces by examining how and why waste emerges within and across the entire commercial food service cycle, comprising menu planning, procurement, receiving, storage, cooking, food service and waste disposal $[29,30]$, in the unique context of luxury hotels.

Drawing on a multimethod study of operational practices, this paper identifies diverse perceptions and practices that lead to food waste at different stages, focusing specifically on the breakfast service cycle within the context of luxury hotels. This is particularly important for three reasons: first, because rooms are often sold on a 'Bed \& Breakfast' basis, and breakfast buffets typically tend to be high-volume operations in hotels; second, the high prices charged by luxury hotels are coupled with expectations of premium quality service; and third, the buffet remains an internationally used service style, which has been identified as a significant driver of food waste $[24,25]$.

\section{Food Waste and the Service Cycle}

There is no universal definition of the term 'food waste'. In fact, different authors have used varied terminology when referring to food waste. For example, it has been referred to as 'wasted food' in the literature [31]. The difference is more than semantic as the authors have emphasised that food was wasted by someone rather than becoming waste through other means. For the purpose of this study, food waste refers to the decrease in the quantity or quality of food resulting from decisions and actions by retailers, food service providers and consumers [32]. The key implication is that food waste is largely attributable to human actions, and therefore the responsibility to modify wasteful behaviours lies with us. This definition refers to what is commonly referred to as avoidable waste. Avoidable food waste 
refers to food thrown away that was, at some point prior to disposal, edible [33]. Needless to say, avoidable food waste can be prevented across the service cycle.

The first stage in the hospitality service cycle is menu planning. Menus have transformed significantly in the last decade, often reflecting sustainable business practices. Prime examples of this shift are the provision of information about nutritional value and provenance [34,35] and offering local food products [36]. Menus can also be engineered to offer less wasteful dishes and menus have the power to steer consumer choices to favour more environmentally-friendly and socially responsible ones [37]. Regular review of the menu can help to identify slower-moving items, as these are more likely to result in wastage due to spoilage. Still, many hospitality establishments offer extensive menus requiring a vast range of food inventories, which can be a prime reason for wastage [34].

Procurement, the second stage in the food cycle, is defined as the process of obtaining the right products at the right time and in the form that meets pre-established standards set by the organisation [38]. An important omission in this definition is 'in the right quantity'. This is even more critical in the context of food procurement as over-ordering may lead to waste through deterioration, while under-ordering may result in menu items being unavailable. Primarily driven by such concerns, $80 \%$ of restaurant managers surveyed in a recent study reported that they engaged in controlled purchasing with the aim of reducing food stocks and consequent waste [14]. Nevertheless, food procurement within hospitality can often be challenging due to consumers' exacting demands, leading to purchase decisions that can result in negative environmental consequences. This is likely to be especially true for the luxury hospitality sector, which targets discerning segments and charges premium prices.

The third stage of the food cycle, receiving, refers to the process of assessing the delivered food items for specified quantity and quality [29]. Food deliveries are typically accepted only after passing receiving checks. Examples of standard receiving practices include visual checks of meat and vegetables and verifying dates for canned items. It is easy to see that receiving practices are geared towards waste prevention [29]. Likewise, appropriate storage helps to maintain the quality and nutritional value of food products, which in turn minimises wastage. Standard storage practices in hotels include FIFO (firstin-first-out) and maintaining suitable storage conditions, controlling temperature and humidity. At the same time, holding the correct level of stocks is important as too much may lead to spoilage, while understocking poses the risk of running out [29].

Preparation, the next stage in the food cycle, includes activities such as washing, cleaning, filleting, peeling, pre-cooking, cooking and holding food in preparation for service. Preparation is the single biggest contributor to food waste in food service establishments, accounting for $45 \%$ of food waste generated in hotel kitchens [5]. Service style can also profoundly affect food waste. Buffet service in particular has been shown to be a major contributor to wastage of food due to overproduction and poor portion control [20]. However, buffets remain popular due to ease of service and lower labour cost. The COVID-19 crisis has forced many operators to review their use of buffets, although it is not clear at this point whether this is likely to result in longer-term changes in their use [39].

The 'Food Waste Hierarchy' advocates that businesses should seek to reuse food that is edible but has not been served to customers by redistributing rather than disposing of it [40]. Landfill has been placed at the bottom of the hierarchy of preferred waste management methods. Many scholars have examined the use of sustainable disposal methods for hospitality businesses, such as recycling of food that is no longer edible. The use of sustainable disposal methods has had mixed results, partly because of the varied legislative requirements and costs associated with them. For instance, a study found that many hotels in the UAE donated surplus food to charities [20]. Research located in Switzerland made similar recommendations, donating food to local charities [41]. Another study concluded that $60 \%$ of respondents in Vietnam sold food waste to local farms as animal feed [42]. In the UK, it is often difficult to employ many of these redistribution strategies due to strict health and safety standards. For instance, the UK's legislative 
framework prohibits the use of waste food as animal feed and the financial costs of separate food waste collection act as a disincentive for some businesses to seek sustainable disposal options. As a result, much food waste from foodservice establishments in the country is disposed of as mixed waste in large-volume, four-wheeled bins, and is, thus, likely to be destined for landfill or producing energy [5]. In any case, the Food Waste Hierarchy offers clear prescriptive guidelines on waste management, favouring options that lead to more positive social and environmental outcomes. Needless to say, waste prevention has been placed on top of the hierarchy as preventive actions can eradicate the need for sustainable disposal of waste and significantly reduce food procurement costs.

It is evident that food waste is generated across the food service cycle. Though the problem is often attributed to operational areas, management functions such as menu planning and procurement are also likely to influence waste production. For that reason, this study examines the food service cycle holistically as an integrated system. The subsequent discussion considers how the practices that create food waste in the cycle, including the associated perspectives and behaviours of the actors involved, highlight the role of the corporatised operating priorities coupled with the company's value propositions. We argue that these embed multiple organisational practices that render food unusable and minimise the agency of individual staff to challenge these practices.

\section{Materials and Methods}

\subsection{Study Context and Strategy}

This study adopted a multiple, embedded case-study strategy, where attention is given to subunits within a case [43]. The case-study company is one of the largest hotel chains in the world and the research focused on two of their luxury properties. The first was a large, five-star business hotel located in the heart of a major city in Germany. The second was a five-star property located close to a busy international airport in the United Kingdom. The decision to focus exclusively on five-star hotels was driven by the fact that luxury hospitality is viewed synonymously with high brand standards and premium pricing strategies, where quality cannot be compromised [4]. Hence, opportunities to reduce wastage may often be limited, especially when they may be perceived to detract from five-star experiences. These types of operations thus acted as exemplary, data-rich 'intense' cases [44], which helped to capture and understand a phenomenon. In this case, focusing on these types of case organisations served to identify and explore competing tensions and priorities across the service cycle, which may not have manifest themselves in the same way at properties with lower standards and experiential propositions.

Data were collected from multiple departments (units) in the food and beverage area, encompassing the food service cycle in its entirety. The two case-study hotels were chosen purposefully as studying a smaller number of cases provided a better opportunity to explore practices in context and in greater depth. Moreover, having two study operations, with multiple subunits in each helped to identify patterns across both cases.

The hotels were selected using criterion sampling, based on four key criteria; specifically that they: (a) had existing systems for sustainable reporting; (b) could provide basic data on food waste levels; (c) operated on a centralised procurement system; and (d) were part of a hotel chain. This helped with deeper understanding of the business context and provided access to comparable data across both operations and across the subunits. Moreover, this operational configuration can be considered a 'typical' case for this segment within the international luxury hotel sector.

\subsection{Data Collection Methods and Sample}

Data collection methods utilised document analysis, observation and semi-structured interviews, which were carried out over an 8 month period, following approval from the University's Research Ethics Committee. Corporate sustainability reports, menus, standard recipes and inter/intra-departmental communications were examined to establish deeper understanding of the empirical context and standard operational practices. Corporate 
operational documents shed light on company policies and formal procedures (in other words, how things should be done), which were contrasted with observation of employees' behaviours at the workplace (how things were done). Prior to commencing the fieldwork, a pilot study was conducted at a university training restaurant in the UK. The pilot utilised the full range of data collection procedures that were employed in the final study. For the pilot, observations were conducted in the kitchen and storage areas over a period of five days and six semi-structured interviews were conducted with a range of kitchen and operations management staff. Preliminary findings identified through an initial analysis informed the final interview schedule (Appendix A).

Analogous to other qualitative studies in hospitality organisations [45], purposive sampling was used to identify the most relevant people to engage in this study. Based on the key criteria of information richness, members of staff who controlled or influenced food inputs were purposefully selected for interviews. This included 8 senior managers, encompassing the sustainability manager (UK), head chef (Germany), director of finance (UK), general manager (UK and Germany), director of operations (UK and Germany), and food and beverage manager (UK); 6 managers, including the food and beverage controller (UK), assistant restaurant manager (Germany), assistant head chefs (UK and Germany) and sous chefs (UK and Germany); 6 supervisors, including restaurant shift leaders (UK and Germany), back of house supervisor (UK) and junior chefs (UK and Germany); and 3 general-level employees, including kitchen porters and waiting staff (Germany). Sampling employees from all levels and a wide variety of areas, helped to identify a range of competing perspectives and provided balanced insights into people's subjective realities.

A total of 22 formal interviews were conducted, each typically lasting between 45 and $60 \mathrm{~min}$. Of these, 10 were conducted in Germany and 12 in the UK. The key areas of questioning were: their perceptions on food waste, corporate policies to tackle this issue, operational measures implemented within the food service cycle to prevent wastage and any future plans to address food waste. The interviews were audio recorded and transcribed manually. It was evident that many respondents were less guarded and spoke freely before and after the recording was done. Therefore, naturally occurring talk was noted with the permission of the respondents. These formal interviews were complemented by numerous informal discussions with these and other staff throughout the fieldwork.

Recent research has called on further observational studies of food waste practices as part of a triangulation strategy to increase the trustworthiness of findings [23]. Observations were overt and as unobtrusive as possible, and they allowed the researcher to capture and evaluate food waste-related behaviours in their organisational contexts. One researcher from the team played an 'observer-as-participant' role [46]. The observation was not merely passive; instead, the observer actively participated in the daily activities of those observed. This allowed a deeper and nuanced understanding of subjective realities of those observed. Some scholars have noted that (non-)participant observation can be disruptive and can alter the actions of those observed, due to the presence of the researcher [47]. In order to address these concerns about bias, a member of the research team spent significant time at both properties. Furthermore, conscious effort was made to engage in less formal conversations (typically during lunch and dinner breaks) to establish positive relations as well as gather informal insights. The observer also actively participated in carrying out many operational activities. Simple 'paper-and-pencil' recording of data was done as this method is widely regarded as the least invasive. These strategies were immensely helpful as the observer became 'less visible' over time and conversations became less restrictive.

It has been argued that observations can be more representative when they are conducted at different locations and temporal points as there may be heterogeneity [48]. Therefore, observations were conducted over weekdays and weekends. This was important to account for distinctive business patterns. In addition, different members of staff could be observed. From a spatial perspective, observations were not limited to food production areas but also covered other locations such as the receiving bay, storage areas, 
dish wash and service stations. All these factors helped to create a holistic understanding of food waste.

\subsection{Data Analysis and Trustworthiness}

Thematic analysis was employed to analyse primary data [49]. Data sets from the two cases were initially coded separately. This was done to capture the broadest set of codes. During coding, there is inherent risk of some loss of holistic understanding of individual accounts if codes are developed 'out of context' [50]. For that reason, codes were developed using small paragraphs (typically comprising three sentences) as units. It also became apparent that multiple codes were relevant for the same data. In such cases, rather than fitting the data into one code, they were assigned to different codes. The next stage involved focused coding. Overlapping codes were merged and some were discarded as they were deemed to be outside the scope of this research (for example, level of unionisation or customer education).

Subsequently, themes were developed with initial guidance from the literature review and codes were assigned to them. However, many codes did not fit neatly into existing themes and therefore new, emergent themes were developed. This data-driven approach has been widely supported in the literature [21]. The initial thematic map helped to identify how different themes interacted with each other. Thereafter, themes were refined; this involved merging overlapping themes and discarding those that were not sufficiently supported by primary data. Findings naturally assumed the form of a detailed narrative, and verbatim quotes from respondents were included. This helped to capture respondents unique 'voices' while limiting researcher bias.

A number of measures were taken to establish trustworthiness of the findings [51]. First, the views of all stakeholders and not just a dominant few were taken into account. Second, data triangulation was employed [50]. Data gathered through interviews, observation and document analyses were cross-analysed. This helped to explain, support and challenge assumptions. Data obtained from the two case-study hotels were used together to examine convergent and divergent patterns. Furthermore, observations often guided interviews as specific questions were asked in order to comprehend meanings that underpinned people's behaviours. In a similar vein, behavioural patterns were observed in light of responses provided in the interview. This helped to ascertain if actual behaviours were consistent with reported behaviours.

\section{Findings}

Existing research indicates that food waste management is a key concern for hospitality managers [14,42]. This was evident at the case-study hotel company too and numerous corporate initiatives were directed towards addressing this issue. Accordingly, management attempted to implement a variety of measures across all properties to divert food waste from landfill. This was primarily achieved by donating edible food to charities (where doing so was legally permitted). Where redistribution was not possible, food waste digesters were used. Arguably, these initiatives were primarily aimed at diverting waste from landfill rather than prevention. However, the company's attempts at food waste prevention further upstream in the service cycle revealed the priorities and tensions between different actors, their perceptions and behaviours in their enactment. The findings present these through the different key stages of the service cycle.

\subsection{Menu Planning}

Menu planning is typically under the direct control of the management team in larger hotels, though such demarcation may be less pronounced in smaller ones. Managers reflected that they were well aware of the waste reduction potential of efficient menu design.

From menu planning perspective, it's trying to have similar menus [between various outlets in the hotel]. So, room service and lounge for example, the [breakfast and lunch] 
menus are quite similar. What is available on room service menu is exactly the same as what is available in the lounge because the food comes from the lounge. We don't have a separate kitchen running with a chef where we can we try to have a bit of synergies with the menus, and kind of almost not have to double hold stock. (Food \& Beverage Manager, UK)

The case-study hotels implemented numerous measures such as offering lighter menus and kids' portions of regular items. Menus were often shared between two or more areas. However, menu design was guided by customers' expectations of five-star dining experiences and hence choices could not be too restricted. At the case-study hotels, over 80 different varieties of food items were offered on the breakfast buffet. This level of choice was a prime driver of wastage. Interestingly, the buffet menu price also indirectly impacted wastefulness. A UK-based Director of Finances noted:

... And that will daily, won't it, where you will either have a complaint about - that portion did not look big enough for the price we are charging, and we do price very highly. So I think sometimes chef has to make sure his portions are probably on the slightly larger side.

Serving large portions was a mechanism to justify high menu prices, which was typical for a luxury hotel segment. Large portions could also be seen as a mechanism to minimise the risk of complaints. Though such practices resulted in greater amount of plate waste, these were viewed as rational choices. The interviews established that managers were aware of menu engineering practices that could help to prevent food waste from arising. However, it was not always practical to implement preventative measures as external forces may have constrained waste prevention opportunities available to chefs. The pre-designed menus set customer expectations, while the lack of flexibility within a branded corporate setting to (re)organise the menu limited the possibilities for change.

\subsection{Food Procurement}

The case-study hotels operated on a disciplined purchasing system and only specific, approved items could be bought from company nominated suppliers. Therefore, flexibility in selecting food items was restricted. A General Manager in Germany observed:

As a big company, we tend to buy of course from the big suppliers. So, we as a company tend to buy out of economics and out of logistics from big hubs but we do not buy well really from local area. And that means that perhaps food is not as seasonal, as not specific for a hotel. You might buy more in bulk than you might buy if it's more around you, then again you have to be realistic as well.

Lower cost, better value and an efficient delivery system drove food purchase decisions. Bulk buying was the norm, largely due to economies of scale, lower transportation costs and overheads [29,52]. Previous studies have suggested that hotel managers must consider the environmental footprint associated with the food they procure [53]. In contrast, financial and operational considerations rather than sustainability ones primarily drove purchase decisions. This represented a significant point as the savings achieved through a cost-efficient procurement system were valued more than the losses accrued due to wastage. Despite the highly disciplined procurement system, there was some level of flexibility and buying extra was widely considered the norm in both case-study operations:

The main chef in each of the three kitchens order supplies for their section only, adding a bit extra to cover all risks. (Sous Chef, Germany)

Purchase-wise, we try to keep stocks to the minimum but also keep a buffer for consumption. If we run out of food, I'll be the one who will be held responsible. (Breakfast Chef, UK)

Chefs argued that they only ordered small quantities of extra stocks, though these accumulated over time, resulting in waste due to spoilage. Therefore, the practice of procuring extra food stocks could also contribute to wastage. However, respondents 
contended that this also minimised risk of food shortfalls and consequent financial and reputational losses. Chefs feared that running out of menu items might reflect poorly on their own professional reputations and therefore favoured purchasing excessively rather than using their judgement about what amounts were sufficient.

\subsection{Receiving and Storage}

Receiving and storage practices at both hotels were geared towards waste prevention. Rigorous quality checks were performed at the receiving bay and food products that did not meet rigorous quality standards were returned. Furthermore, food items were shifted to storage areas as quickly as possible, which minimised the risk of waste owing to deterioration of quality. For example, a UK Food and Beverage Controller said:

When the food is coming in, really my side, the boys will check what is coming in and the Purchase Order and if it is a really close use-by date, they double check with the chef if they are going to use it within that, if not we will send it back. There are things like packaging quality, if it's broken or whatever, it will get sent back. If it doesn't look right, that will get sent back so they are trying to get the longer life out of it.

On the one hand, it can be argued that standard practices at the receiving bay were guided by concern for food waste. On the other, this might simply indicate an attempt to partly shift the burden of food waste onto suppliers. Similarly, food waste was a key concern that informed routine storage practices at both hotels, for example:

You see my stores, it's not big enough ... it's purposefully there [emphasis in original], when it does get full, we walk in there and go oh! We don't need to order anything. (Head Chef, Germany)

This was also reflected in UK observations:

From a storage point of view, each outlet has its dedicated and localised storage areas, fridges and freezers. This allows easier control as each chef is responsible for monitoring food stocks in his/her own area and the movement of food inventory can be visually overseen quite easily.

Chefs preferred to use small storerooms because it made holding extra stock impractical. This in turn forced the kitchen team to order less, but more frequently. Both hotels also provided localised storage facilities as this helped to monitor food stocks easily. Despite this, significant amounts of food were wasted due to spoilage. Such waste was attributable to the fact that standard storage practices were not always followed.

... It's like they don't check and control what is old, what is fresh and reorganise it, for three days or so I throw away huge amount of ham, because people didn't like put away the old ham and the new one was used and this is a recurring problem [sic]. (Sous Chef, Germany)

Similar issues were identified through observation:

I am in the dry stores—all the food items here are long life, though I do not see much evidence of standard stock control practices such as FIFO. However, the general wisdom is that the stuff will get used up anyway owing to high business volume. (Observation $\log , \mathrm{UK})$

There were many possible reasons for employees not following standard storage practices. One plausible explanation was a general lack of care or concern for food waste. Another was that employees were simply unaware of the magnitude of the problem. The fact that agreed practices were not followed may also reflect lack of fundamental operational knowledge or skills among employees.

\subsection{Food Production}

To begin with, it was evident that not all food products were considered suitable for use. For example, deterioration in the cosmetic properties of food frequently led to such food items being considered unfit for service. Similarly, in many cases, the label rather than 
quality acted as the barometer for usability. This was before such foods had reached the end of their edible life.

If you have fruit that is little bit damaged, that means these fruits are not as pretty as should be, so they are not going to be selling, what are you going to do [with such food items] [sic]? (Waitress, Germany)

Similarly:

We have those best before [dates] ... . so, we throw it away if it's reached this mark. But it's still good, but this is how they taught us. (Assistant Restaurant Manager, Germany)

Observations and interviews shed light on other unique challenges associated with food production within the context of luxury hotels. These venues operated on exacting brand standards; consequently, quality compromises were avoided because of perceived reputational risks.

... say you've got 50 vegetarian ordered, you know you are going to get more than that, therefore we will cater for more than that. But what we can't do is, say you are catering for 50 vegetarians, you can't say, we will cook 50 less meat portions, just in case! You can't take the risk. (Director of Operations, UK)

In another incident:

I just witnessed that four full trays of fried eggs were thrown away. This is a clear case of overproduction. This was possibly avoidable had the chef resorted to batch cooking in the last hour of service. (Observation log, Germany)

Importantly, there were market and brand-based drivers to these behaviours, which became embedded in the pervasive workplace culture:

The chef warns me against the use of the word 'extra', he argues that nothing is cooked extra as it has all been paid for by the guest and therefore the food needs to be provided for them. (Observation log, UK)

Cooking surplus was widely considered the norm at the case-study hotels. Though overproduction was a prime reason for food waste, chefs rationalised it and viewed surplus food as a 'margin of safety' and part of the 'five-star service' offering. In addition, bulk cooking and pre-cooking were common as these helped to shorten service times and saved labour. Such practices were also widely accepted, as it was often difficult to predict the number of diners. Bulk cooking and pre-cooking effectively covered any perceived risk of food shortfalls in case the service got busy. However, bulk cooking could lead to surplus food production, as quantities were difficult to control. Pre-cooking also led to waste as the quality of food items deteriorated over time. It was observed that bulk and pre-cooking continued into lean business periods and when standard recipes advocated it for specific food items. The implications of these normative practices for food waste were evident:

They get so used to doing busy numbers that when the numbers drop and its quiet, sometimes they can over prepare and it's like well, you didn't need to chop that up, and it would have stayed another week, but now you've chopped it up ... so, when its quieter I think we tend to get more waste. (Junior Sous Chef, UK)

\subsection{Food Service}

Despite being inherently wasteful, buffets remain popular due to ease of service and lower labour cost. Buffet service is especially favoured for breakfast as patrons have little time on hand and self-service is more efficient. Both case-study hotels provided extensive choices for breakfast, in line with the brand standards, even though their potential for waste was recognised.

First, we have the policy that the buffet has to be full 100\% till the last minute. That means some of the food that we have on the buffet, will [go to waste], we actually cannot bring it in [to be reused]. (Waitress, Germany) 
You need to have a certain look at the buffet, you need a full buffet with everything is on and the guests need to see it, he wants to see it, if you arrive at 6.30 or 10.30, it doesn't matter, there must be a complete, full buffet [sic]. (Assistant Restaurant Manager, Germany)

Interview respondents identified multiple reasons for the high volume of waste arising from buffet service. Patrons often did not consume breakfast, but the hotel was obliged to provide catering services for the numbers booked. The service team normally planned multiple buffet stations in order to ease movement and to avoid guests having to wait for food. This acted as fertile ground for wastage. In addition, it was common practice to keep the buffet full at all times. These practices reflected high service quality, customer expectations and value propositions consistent with luxury hotel experiences. Furthermore, there were strict legalities that governed the reuse of food displayed on the buffet. Therefore, food safety concerns and fear of legal liability overrode waste prevention goals [54]. Moreover, the quality of food items deteriorated over time, making them unsuitable for service or reuse. Owing to these factors, most respondents affirmed that it was 'safer' to discard food than to reuse it. Respondents felt that there was little that could have been done to control the wastage of food.

\subsection{Waste Disposal}

Lastly, staff observations on waste disposal provided an additional perspective. It was evident that the focus at both hotels was on reuse or sustainable disposal of food rather than on prevention. This was consistent with the parent hotel company's Corporate Social Responsibility (CSR) report and therefore reflected the corporate approach towards food waste management. The senior managers explained the sustainable disposal systems that had been put into place.

From our food waste, they produce energy, say at the end, it's a cycle, there is a value behind. We are aware that we are producing a lot of waste, spending a lot of money to get it out of the building, but in terms of environment and in terms of responsibility, I think we have a good way, we are on a good shape [sic]. (Director of Operations, Germany)

We are looking at a different way of [dealing with food waste] ... instead of disposing we are looking at one of these digesters that decomposes food. We still have the same amount of food waste, it does not change that, it just means that it does not go off site to wherever it goes. (Head of Sustainability, UK)

It was evident that sustainable disposal was considered an alternative environmentallyfriendly option with merit over-and-above food waste prevention. This could partly be an outcome of the fact that food waste was largely considered unavoidable. Therefore, sustainable disposal or reuse were generally seen as rational strategies compared to waste prevention. This may also suggest that hotel employees may not necessarily view waste prevention as a separate activity to sustainable disposal. Arguably, sustainable disposal options might serve as mechanisms for managers to address the problem in a guilt-free manner as they may feel that they had 'done their bit'. In reality, sustainable waste disposal may counteract preventative thinking as it does not lead to a reduction in the amount of food waste but can only limit the damage. One case-study hotel attempted to reuse surplus food items by redirecting them to the staff canteen. This practice offered further unique insights into operational practices and their consequences.

I just witnessed that a 240-litre bin in the staff canteen is almost full to the brim. It seems that all other kitchens bring all their surplus food to the canteen. The canteen cannot cope with the volumes of food coming from other kitchens and being at the end of food chain, throw away all the surplus foods. (Observation log, UK)

The hotel's internal reuse system signalled that chefs were content to shift the problem from their area. Chefs assumed that since surplus food items could be reused, cooking extra was less of a concern. It was evident that the practice of redirecting food surpluses to staff canteen was simply tokenistic and may have represented an 'out of sight, out of mind' 
mentality towards food waste. The fact that food eventually found its way into the bin (though in the canteen area) may not even have registered as waste in the chefs' minds as arguably they had played their part by attempting to reuse the food. This finding suggests that only immediate food waste was actively recognised.

\section{Discussion}

Firstly, it is appropriate to reconsider the terminology associated with food waste. Much of the existing research has referred to avoidable and unavoidable food waste $[55,56]$. Waste was categorised as avoidable or unavoidable depending on whether food was edible or not [19]. However, within the context of the hospitality industry, edible foods may not always be consumed, thus becoming 'unusable' because of other subjective criteria such as cosmetic properties, labelling and perceived quality. In other words, food that is edible, and in principle 'usable', may be designated 'unusable' and thus wasted because of wider, deeply embedded organisational practices. We therefore propose that food may be referred to as usable and unusable, while making it clear that usability is distinct from edibility in the hospitality context. This difference in terminology is more than semantic, and adopting this terminology has specific implications in this context as the data have helped to identify the processes and practices that rendered foodstuffs unusable within a corporate luxury hotel context.

Previous studies have acknowledged that hotel policy is a contributing factor in food waste creation $[57,58]$. Extending this point, the data in this study stressed that the luxury value proposition promotes indulgence, which is often incompatible with sustainable practice. Importantly, the coupling of the luxury proposition with a corporatised, global branding strategy embeds this throughout the entire organisational culture. The data highlighted that food waste prevention was viewed as a risky strategy that could impact guest experience negatively. Quality compromises were avoided as they represented risks insofar as they were potential sources of service failure, incurring professional sanctions for actors engaged across different stages of the service cycle.

Research has suggested positive links between the adoption of sustainability strategies and brand value in corporate hotel chains [59]. However, primary data from qualitative studies have also suggested that operational staff may be apprehensive about engaging in food waste related sustainable behaviour that contradicted corporate set standards [60]. The data in this study highlighted how corporatised value propositions linked to brand standards compromised attempts at food waste reduction across the service cycle. For example, this included the strict standards adopted during purchasing conventions, receiving goods, and the prescribed need to follow labelling advice rather than making independent judgements regarding the usability of food [4]. This was found to be the case at both case-study hotels, further indicating that employees' work behaviours were deeply embedded within organisational contexts. Furthermore, obvious cultural differences between Germany and the UK did not manifest themselves in either observed or reported behaviours. Arguably, this finding suggests that corporate cultures can be stronger than national ones in shaping work-related practices.

The data emphasised how corporate brand values and standard operating practices risked systematically rendering food unusable across the service cycle. Importantly, the desire to construct and maintain a global brand resulted in food wastage becoming embedded in the organisational culture and practices of corporate subunits. Hotel managers were acutely conscious of food costs. However, savings achieved through bulk buying and efficient delivery systems were weighted more favourably in comparison to losses accrued due to waste and disposal costs. This can be explained by the contrasting expectations presented by the company's value propositions and the perceived business risks associated with waste minimisation [4]. As the data showed, managers attempted to rationalise this waste by viewing it as a 'part of the luxury experience', and one that 'has been paid for' by the guest. This reflected the normalisation of the fundamental processes that potentially rendered foods unusable across the service cycle. 
It is evident that food waste is a complex issue, since waste can be attributed to multiple stages of the hospitality food service cycle $[57,60]$. The dynamics of the corporate luxury sector may make it particularly difficult to enact food waste reduction as individual agency is subordinated to structural constraints, perpetuated through the branded value proposition and instilled in corporate processes [4]. The hotels' management teams were well aware of the potential for waste prevention; nevertheless, food waste persisted. The data suggested that food waste was considered inevitable and many felt that little could be done to address the problem. In other words, despite knowledge of and concern for food waste prevention, employees may have limited (perceived) capacity to implementing preventative measures shaping what is designated usable or unusable. These findings reinforce the problem that concerns for sustainability related issues and the corporate policies do not necessarily translate into effective environmental actions in the workplace.

More specifically, sustainability as corporate discourse may be problematic in part because of how it frames the issue of food waste in CSR strategies, which are also part of its corporate communications and branding decisions. The framing of the problem informs how it shapes operational policies and practices [61]. If waste management within these strategies focuses on practices that avoid food going to landfill, rather than elimination of wasteful processes elsewhere in the service cycle, they will not impact perceptions, attitudes and behaviours towards usability of foodstuffs elsewhere in the cycle.

Furthermore, corporate policy also translates into corporate culture, as embedded social practice [62], into which staff are socialised. This study, like others, has shown that employees tended to attach different meanings to food waste, depending on their own perspectives [26]. However, it is important to stress that hotel staff at all levels, in their various interactions in the service cycle, internalise the organisational cultures that reflect the company's global image and premium value propositions. This inevitably frames their 'sensemaking processes' [63], in this case regarding usability and sustainable practice. Boundaries were therefore not always be clearly established and hence chefs, for example, may have been unable to distinguish between waste prevention and sustainable disposal. In a similar vein, employees at various levels of the organisational hierarchy may approach the issue from disparate perspectives. While managers principally equated food waste with cost, supervisors were more concerned about everyday practicalities and how addressing wastage may impact their routine work practices. At the same time, general staff evaluated waste prevention as compromising cultural norms of a luxury hotel's services.

\section{Conclusions and Implications}

This paper has outlined how multiple agendas directly compete with waste prevention initiatives. Moreover, it has highlighted how essential aspects of the organisational context, in this case, as a corporate luxury hotel brand, have the potential to shape these agendas and their enactments. The findings suggested that these present deeply embedded structural problems; consequently, a systemic approach to waste prevention is needed that extends beyond the food cycle and which includes within its scope the broader hotel operating systems and processes. All activities within the food service cycle are interlinked and affect one another. Moreover, practices across the service cycle are shaped by the corporatised design and value propositions.

It is argued here that integrated management systems are required to control and regulate food handling activities. For example, centrally designed menu streamlining can ensure that, whenever possible, ingredients can be shared between various dishes on the menu. Menu engineering that utilises shared data across different organisational subunits can help managers identify food products (and practices) that are more prone to wastage. Previous studies have suggested that embedding self-reporting practices [64] and making waste 'visible' during the production cycle [65] can be used to promote food waste reduction behaviours.

The important point, however, is to deploy these interventions across the corporation, through its established global governance structures. Such centrally designed and driven 
interventions also extend to other points in the service cycle. For example, contracts can be negotiated with suppliers for smaller food packaging and greater numbers of regular supplies. This can minimise the need to carry excessive food inventories, although these strategies also create transport related pollution, so its aggregated benefits and risks should be evaluated based on a wide set of indicators. Controlled purchasing can also be informed by better demand forecasting, which is underpinned by corporately designed and operated data gathering and processing capacities. Intelligent stock control systems can help to ensure that only optimum quantity of food items are kept in storage and under suitable conditions. Artificial intelligence-based systems can also help minimise wastage attributable to spoilage.

Buffet service systems can be redesigned to provide a customised, added-value service experiences. For instance, rather than presenting food in bulk at stations, live, a la minute cooking stations can help to reduce waste as food is cooked to order. This could also help portion control; but, significantly for this type of luxury offering, the value proposition emphasises food quality and personalisation rather than quantity.

However, this analysis of the service cycle within the context of a corporate business model also points to the potential limitations of this type of organisational strategy for managing food waste. This concerns the ways in which waste is conceived at a corporate level, and the potential inflexibility of organisational strategies, in particular to the ways they culturally embed perceptions of and attitudes towards waste, in relation to brand standards and value propositions.

For those engaged in delivering sustainability initiatives in corporate hotel businesses, the evidence that emerges from this study highlights the complex nature of this issue. In particular, this study sheds new light on two issues that are significant for developing sustainability programmes. The first of these is the way in which corporate processes can negate individual agency. The findings demonstrate how conflicting messages that arise from different elements of the corporate communication chain can influence perceptions among one group of actors (employees) and undermine their propensity to engage in pro-environmental behaviours. Thus, it is important for organisational designers to remain conscious about how such cultural embedding negates individual agency to challenge conventions and processes, and to enact constructive change at a local level. Specifically, how individual actors are empowered to intervene at various points in and across the food service cycle to change how food is rendered usable or unusable.

The second highlights the significance of behaviour change when seeking to prevent food waste from arising. Food waste differs from resource efficiency in the areas of energy and water management. In energy and water management, technology is frequently employed alongside changes in staff behaviour as a means to reduce costs and environmental impacts. In the area of food, many of the current technologies have the capacity primarily to deliver savings in waste disposal costs (diverting waste from landfill and into energy or compost). However, greater resource and cost saving opportunities lie in preventing food waste from arising. Achieving this requires enhanced understanding about the means for delivering pro-environmental behaviour changes.

\section{Limitations and Recommendations for Future Research}

The findings of this study were based on data collected from a small sample of five-star hotels and hence may not be truly reflective of other analogous operations, operations of different grades, or food service providers such as cafés, restaurants or fast food outlets. Future research could therefore expand the overall sample size, alongside the comparative elements of enquiry, selecting hotels with a wider range of value propositions and service standards, and also considering similarities and differences between independent operators and those part of wider conglomerates. The economic ramifications of waste in luxury hotels can also be investigated. This could, for example, be done by measuring and quantifying food waste and assigning monetary value to it. Such a cost-based methodology 
may be particularly effective in driving corporate-level initiatives that seek to transform employees' attitudes, behaviours and workplace practices.

Further studies could also adopt participatory, impact-driven agenda in attempting to design and implement interventions at and across the service cycle. This study focused primarily on production spheres and their actors. Future action research can maintain a production focus, assessing the consequences of interventions on waste generation and prevention practices, and waste levels. However, evaluating those interventions might encompass a consumer focus, capturing impacts on perceptions of value, service quality and satisfaction among luxury customer segments.

Future studies can also focus more explicitly on the processes of CSR framing, assessing in particular how corporate-level conceptions of food waste problems translate into practices, particularly among the operational staff, in front and back of house roles, who have to negotiate the challenges of service provision and sustainability pressures. Studies can also examine how corporate-level policies influence staffs' sense of psychological empowerment and their agency to improve food waste management across the service cycle.

Author Contributions: G.C.: conceptualisation, methodology, investigation, formal analysis, writingoriginal draft, visualisation, and project administration. P.L.: conceptualisation, methodology, formal analysis, writing—original draft, visualisation, and supervision. R.H.: conceptualisation, methodology, formal analysis, writing - review and editing, and supervision. All authors have read and agreed to the published version of the manuscript.

Funding: This research received no external funding.

Institutional Review Board Statement: This study was conducted according to the guidelines of the Declaration of Helsinki, and approved by the Ethics Committee of Oxford Brookes University (Ref: 160998).

Informed Consent Statement: Informed consent was obtained from all subjects involved in this study.

Data Availability Statement: The data presented in this study are available on request from the corresponding author. The data are not publicly available due to a confidentiality agreement with the participating organisation.

Conflicts of Interest: The authors declare no conflict of interest.

\section{Appendix A. Interview Schedule}

What is food waste in your opinion?

To what extent is food waste seen as an area of concern in the hotel?

What are the specific policies/procedures in place at the unit level to address this challenge? In your view, what are the main reasons owing to which food ends up being wasted in routine operations of the hotel?

Tell me about your experience of food waste management in this organisation. What initiatives have been tried in the past?

Could you talk me through some of the other behaviour change initiatives that have been implemented in the hotel in the past? What was done and how?

What was the outcome of such initiatives?

What is the role of procurement/receiving/storage/kitchen/service departments in preventing food waste?

Who are the key people involved and how?

Tell me about your interactions with other departments. Is food waste something that is often discussed and communicated?

What are the future plans to address this challenge (training, infrastructure provision, measuring food waste)?

Any other comments or feedback that you think might be relevant to this research? 


\section{References}

1. Thyberg, K.; Tonjes, D. Drivers of food waste and their implications for sustainable policy development. Resour. Conserv. Recycl. 2016, 106, 110-123. [CrossRef]

2. Benton, T.; Bieg, C.; Harwatt, H.; Pudasaini, R.; Wellesley, L. Food System Impacts on Biodiversity Loss: Three Levers for Food System Transformation in Support of Nature; Chatham House Research Paper; Chatham House: London, UK, 2021.

3. Environment, Food and Rural Affairs Committee. Available online: https://publications.parliament.uk/pa/cm201617/cmselect/ cmenvfru/429/429.pdf (accessed on 14 January 2019).

4. Filimonau, V.; Coteau, D. Food waste management in hospitality operations: A critical review. Tour. Manag. 2019, 71, 234-245. [CrossRef]

5. Waste Resource Action Programme. Available online: https://wrap.org.uk/sites/default/files/2020-10/WRAP-Overview\%20of\%20 Waste\%20in\%20the\%20UK\%20Hospitality\%20and\%20Food\%20Service\%20Sector\%20FINAL.pdf (accessed on 19 April 2021).

6. Waste Resource Action Programme. Available online: https://wrap.org.uk/sites/default/files/2020-09/UK-progress-againstCourtauld-2025-targets-and-UN-SDG-123.pdf (accessed on 14 April 2021).

7. Food and Agriculture Organisation. Available online: http://www.fao.org/3/a-i2697e.pdf (accessed on 1 April 2021).

8. Reuters. Available online: https://www.reuters.com/article/us-food-waste-idUSBRE9090TN20130110 (accessed on 19 March 2021).

9. The Guardian. Available online: https://www.theguardian.com/environment/2013/jan/10/half-world-food-waste\#: \{\}$: t e x t=$ As\%20much\%20as\%20half\%20of,a\%20report\%20published\%20on\%20Thursday (accessed on 9 April 2021).

10. Papargyropoulou, E.; Lozano, R.; Steinberger, J.; Wright, N.; Bin Ujang, Z. The food waste hierarchy as a framework for the management of food surplus and food waste. J. Clean. Prod. 2014, 76, 106-115. [CrossRef]

11. Food and Agriculture Organisation. Available online: http://www.fao.org/3/i3347e/i3347e.pdf (accessed on 17 April 2021).

12. UNICEF. Available online: https://www.unicef-irc.org/publications/pdf/IWP_2017_09.pdf (accessed on 24 April 2021).

13. United Nations. Available online: https://unstats.un.org/sdgs/files/report/2017/TheSustainableDevelopmentGoalsReport201 7.pdf (accessed on 19 April 2021).

14. Principato, L.; Pratesi, C.; Secondi, L. Towards zero waste: An exploratory study on restaurant managers. Int. J. Hosp. Manag. 2018, 74, 130-137. [CrossRef]

15. European Commission. Available online: https://www.eu-fusions.org/phocadownload/Publications/Estimates $\% 20$ of $\% 20$ European\%20food\%20waste\%20levels.pdf (accessed on 19 April 2021).

16. Environmental Protection Agency. Available online: https://www.epa.gov/sites/production/files/2020-11/documents/2018 _wasted_food_report-11-9-20_final_.pdf (accessed on 5 June 2021).

17. Waste Resource Action Programme. Available online: http://www.wrap.org.uk/sites/files/wrap/Estimates_\%20in_the_UK_ Jan17.pdf (accessed on 29 April 2021).

18. Waste Resource Action Programme. Available online: https://wrap.org.uk/resources/report/uk-progress-against-courtauld-20 25-targets-and-un-sustainable-development-goal-123 (accessed on 6 June 2021).

19. Papargyropoulou, E.; Wright, N.; Lozano, R.; Steinberger, J.; Padfield, R.; Ujang, Z. Conceptual framework for the study of food waste generation and prevention in the hospitality sector. Waste Manag. 2016, 49, 326-336. [CrossRef]

20. Pirani, S.; Arafat, H. Reduction of food waste generation in the hospitality industry. J. Clean. Prod. 2016, 132, 129-145. [CrossRef]

21. Radwan, H.; Jones, E.; Minoli, D. Solid waste management in small hotels: A comparison of green and non-green small hotels in Wales. J. Sustain. Tour. 2012, 20, 533-550. [CrossRef]

22. Filimonau, V.; Krivcova, M.; Pettit, F. An exploratory study of managerial approaches to food waste mitigation in coffee shops. Int. J. Hosp. Manag. 2019, 76, 48-57. [CrossRef]

23. Okumus, B.; Taheri, B.; Giritlioglu, I.; Gannon, M.J. Tackling food waste in all-inclusive resort hotels. Int. J. Hosp. Manag. 2020, 88, 102543. [CrossRef]

24. Filimonau, V.; Nghiem, V.N.; Wang, L.E. Food waste management in ethnic food restaurants. Int. J. Hosp. Manag. 2021, $92,102731$. [CrossRef]

25. Juvan, E.; Grün, B.; Dolnicar, S. Biting off more than they can chew: Food waste at hotel breakfast buffets. J. Travel Res. 2018, 57, 232-242. [CrossRef]

26. Goh, E.; Jie, F. To waste or not to waste: Exploring motivational factors of Generation Z hospitality employees towards food wastage in the hospitality industry. Int. J. Hosp. Manag. 2019, 80, 126-135. [CrossRef]

27. Luu, T. Reducing food waste behaviour among hospitality employees through communication: Dual mediation paths. Int. J. Contemp. Hosp. Manag. 2020, 32, 1881-1904. [CrossRef]

28. Okumus, B. How do hotels manage food waste? Evidence from hotels in Orlando, Florida. J. Hosp. Mark. Manag. 2020, 29, 291-309. [CrossRef]

29. Cousins, J.; Foskett, D.; Graham, D.; Hollier, A. Food and Beverage Management; Goodfellow Publishers Limited: Oxford, UK, 2010.

30. Environmental Protection Agency. Available online: http://www.foodwaste.ie/web-images/Food-Waste-Prevention-Guide.pdf (accessed on 21 January 2021).

31. Neff, R.; Spiker, M.; Truant, P. Wasted food: US consumers' reported awareness, attitudes and behaviour. PLoS ONE 2015, 10, e0127881. [CrossRef] 
32. Food and Agriculture Organisation. Available online: http://www.fao.org/platform-food-loss-waste/en/ (accessed on 19 April 2021).

33. Waste Resource Action Programme. Available online: https:/ /wrap.org.uk/resources/guide/waste-prevention-activities/food\#: $\sim\{\}:$ text=Avoidable\%20food\%20waste\%20--\%20food\%20and,bread\%2C\%20apples\%2C\%20meat) (accessed on 17 April 2021).

34. Filimonau, V.; Krivcova, M. Restaurant menu design and more responsible consumer food choice: An exploratory study of managerial perceptions. J. Clean. Prod. 2017, 143, 516-527. [CrossRef]

35. Tsai, C.; Lu, P. Authentic dining experiences in ethnic theme restaurants. Int. J. Hosp. Manag. 2012, 31, 304-306. [CrossRef]

36. Price, S.; Viglia, G.; Hartwell, H.; Hemingway, A.; Chapleo, C.; Appleton, K.; Saulais, L.; Mavridis, I.; Perez-Cueto, F.J. What are we eating? Consumer information requirement within a workplace canteen. Food Qual. Prefer. 2016, 53, 39-46. [CrossRef]

37. Kang, J.; Jun, J.; Arendt, S. Understanding consumers' healthy food choices at casual dining restaurants: Using the value-attitudebehaviour model. Int. J. Contemp. Hosp. Manag. 2015, 48, 12-21. [CrossRef]

38. Payne-Palacio, J.; Theis, M. Foodservice Management, 12th ed.; Pearson Education: Hoboken, NJ, USA, 2008.

39. Komenda, E. Las Vegas Buffets Have Disappeared. Workers Are Now Left Wondering: What's Next? Reno Gazette Journal. Available online: https:/ / eu.rgj.com/story/news/2021/03/05/las-vegas-buffets-disappear-workers-wondering-what-next/ 6753025002/ (accessed on 5 June 2021).

40. United States Environmental Protection Agency. Available online: https://www.epa.gov/sustainable-management-food/foodrecovery-hierarchy (accessed on 20 April 2021).

41. Betz, A.; Buchli, J.; Göbel, C.; Müller, C. Food waste in the Swiss food service industry-Magnitude and potential for reduction. Waste Manag. 2015, 35, 218-226. [CrossRef] [PubMed]

42. Trung, D.N.; Kumar, S. Resource use and waste management in Vietnam hotel industry. J. Clean. Prod. 2005, 13, 109-116. [CrossRef]

43. Yin, R. Case Study Research: Design and Methods, 3rd ed.; Sage: Thousand Oaks, CA, USA, 2008.

44. Patton, M. Qualitative Evaluation and Research Methods, 4th ed.; Sage: Thousand Oaks, CA, USA, 2015.

45. Arendt, S.W.; Roberts, K.R.; Strohbehn, C.; Ellis, J.; Paez, P.; Meyer, J. Use of qualitative research in foodservice organisations. Int. J. Contemp. Hosp. Manag. 2011, 24, 820-837. [CrossRef]

46. DeWalt, K.M.; DeWalt, B.R. Participant Observation: A Guide for Fieldworkers, 2nd ed.; AltaMira Press: Plymouth, UK, 2011.

47. Vinten, G. Participant observation: A model for organisational investigation. J. Manag. Psychol. 1994, 9, 30-38. [CrossRef]

48. Gomm, R.; Hammersley, M.; Foster, P. Case Study Method; Sage: London, UK, 2000.

49. Braun, V.; Clarke, V. Using thematic analysis in psychology. Qual. Res. Psychol. 2006, 3, 77-101. [CrossRef]

50. Brooks, J.; McCluskey, S.; Turley, E.; King, N. The utility of template analysis in qualitative psychology research. Qual. Res. Psychol. 2015, 12, 202-222. [CrossRef]

51. Seale, C. Quality in qualitative research. Qual. Inq. 1999, 5, 465-478. [CrossRef]

52. Roy, H.; Ballantine, P.W. Preferences and attitudes toward locally produced food sourcing in wholesale distributors: Restaurant and chef perspectives. J. Hosp. Tour. Manag. 2020, 45, 544-558. [CrossRef]

53. Cavagnaro, E. The food and beverage department: At the heart of a sustainable hotel. In Guests on Earth: Sustainable Value Creation in Hospitality; Cavagnaro, E., Ed.; Goodfellow Publishers: Oxford, UK, 2018; pp. 274-299.

54. Sakaguchi, L.; Pak, N.; Potts, M. Tackling the issue of food waste in restaurants: Options for measurement method, reduction and behavioural change. J. Clean. Prod. 2018, 180, 430-436. [CrossRef]

55. Nicholes, M.J.; Quested, T.E.; Reynolds, C.; Gillick, S.; Parry, A.D. Surely you don't eat parsnip skins? Categorising the edibility of food waste. Resour. Conserv. Recycl. 2019, 147, 179-188. [CrossRef]

56. McAdams, B.; von Massow, M.; Gallant, M.; Hayhoe, M.A. A cross industry evaluation of food waste in restaurants. J. Foodserv. Bus. Res. 2019, 22, 449-466. [CrossRef]

57. Kasavan, S.; Mohamed, A.F.; Halim, S.A. Drivers of food waste generation: Case study of island-based hotels in Langkawi, Malaysia. Waste Manag. 2019, 91, 72-79. [CrossRef]

58. Dhir, A.; Talwar, S.; Kaur, P.; Malibari, A. Food waste in hospitality and food services: A systematic literature review and framework development approach. J. Clean. Prod. 2020, 270, 122861. [CrossRef]

59. Chen, L.F. Hotel chain affiliation as an environmental performance strategy for luxury hotels. Int. J. Hosp. Manag. 2019, 77, 1-6. [CrossRef]

60. Papargyropoulou, E.; Steinberger, J.K.; Wright, N.; Lozano, R.; Padfield, R.; Ujang, Z. Patterns and causes of food waste in the hospitality and food service sector: Food waste prevention insights from Malaysia. Sustainability 2019, 11, 6016. [CrossRef]

61. Moggi, S.; Bonomi, S.; Ricciardi, F. Against food waste: CSR for the social and environmental impact through a network-based organizational model. Sustainability 2018, 10, 3515. [CrossRef]

62. Hennchen, B. Knowing the kitchen: Applying practice theory to issues of food waste in the food service sector. J. Clean. Prod. 2019, 225, 675-683. [CrossRef]

63. Sonenshein, S. The role of construction, intuition, and justification in responding to ethical issues at work: The sensemakingintuition model. Acad. Manag. Res. 2007, 32, 1022-1040. [CrossRef] 
64. Leverenz, D.; Hafner, G.; Moussawel, S.; Kranert, M.; Goossens, Y.; Schmidt, T. Reducing food waste in hotel kitchens based on self-reported data. Ind. Mark. Manag. 2021, 93, 617-627. [CrossRef]

65. Chawla, G.; Lugosi, P.; Hawkins, R. Evaluating materiality in food waste reduction interventions. Ann. Tour. Res. Empir. Insights 2020, 1, 1-3. 